\title{
East Asian Monsoon controls on the inter-annual variability in precipitation isotope ratio in Japan
}

\author{
N. Kurita ${ }^{1}$, Y. Fujiyoshi ${ }^{2}$, T. Nakayama ${ }^{3}$, Y. Matsumi ${ }^{3}$, and H. Kitagawa ${ }^{1}$ \\ ${ }^{1}$ Graduate School of Environmental Studies, Nagoya University, Furo-cho, Nagoya, 464-8601, Japan \\ ${ }^{2}$ Institute of Low Temperature Science, Hokkaido University, Kita-19 Nishi-8, Sapporo, 060-0819, Japan \\ ${ }^{3}$ Solar-Terrestrial Environment Laboratory, Nagoya University, Furo-cho, Nagoya, 464-8601, Japan \\ Correspondence to: N. Kurita (kurita.naoyuki@e.mbox.nagoya-u.ac.jp)
}

Received: 27 August 2014 - Published in Clim. Past Discuss.: 2 October 2014

Revised: 26 January 2015 - Accepted: 30 January 2015 - Published: 25 February 2015

\begin{abstract}
To elucidate the mechanism for how the East Asian Monsoon (EAM) variability have influenced the isotope proxy records in Japan, we explore the primary driver of variations of precipitation isotopes at multiple temporal scales (event, seasonal and inter-annual scales). Using a new 1-year record of the isotopic composition of event-based precipitation and continuous near-surface water vapor at Nagoya in central Japan, we identify the key atmospheric processes controlling the storm-to-storm isotopic variations through an analysis of air mass sources and rainout history during the transport of moisture to the site, and then apply the identified processes to explain the inter-annual isotopic variability related to the EAM variability in the historical 17-year long Tokyo station record in the Global Network of Isotopes in Precipitation (GNIP).

In the summer, southerly flows transport moisture with higher isotopic values from subtropical marine regions and bring warm rainfall enriched with heavy isotopes. The weak monsoon summer corresponds to enriched isotopic values in precipitation, reflecting higher contribution of warm rainfall to the total summer precipitation. In the strong monsoon summer, the sustaining Baiu rainband along the southern coast of Japan prevents moisture transport across Japan, so that the contribution of warm rainfall is reduced. In the winter, storm tracks are the dominant driver of storm-to-storm isotopic variation and relatively low isotopic values occur when a cold frontal rainband associated with extratropical cyclones passes off to the south of the Japan coast. The weak monsoon winter is characterized by lower isotopes in precipitation, due to the distribution of the cyclone tracks away from the southern coast of Japan. In contrast, the northward
\end{abstract}

shift of the cyclone tracks and stronger development of cyclones during the strong monsoon winters decrease the contribution of cold frontal precipitation, resulting in higher isotopic values in winter precipitation. Therefore, year-to-year isotopic variability in summer and winter Japanese precipitation correlates significantly with changes in the East Asian summer and winter monsoon intensity $(R=-0.47$ for summer, $R=0.42$ for winter), and thus we conclude that the isotope proxy records in Japan should reflect past changes in the East Asian Monsoon. Since our study identifies the climate drivers controlling isotopic variations in summer and winter precipitation, we highlight the retrieval of a record with seasonal resolution from paleoarchives as an important priority.

\section{Introduction}

The East Asian Monsoon (EAM) is a dominant climatic phenomenon over the East Asia region. The thermal contrast between the Asian continent and the Pacific Ocean causes a seasonal reversal of the monsoon winds and alternation of cold winter and warm summer (e.g., Webster et al., 1998; Ding and Chan, 2005; Trenberth et al., 2006). The EAM is the main factor that determines climate and its variability over East Asia, covering eastern China, South Korea, and Japan. Monsoon variability has extensive influence on the agriculture, human lives, and economics of East Asian countries (e.g., Huang et al., 2007; Tao et al., 2008). Thus, knowledge of the future variability of the EAM system that accompanies global change is of great concern for sustainable development in this region. An understanding of its past variability 
a) JJA

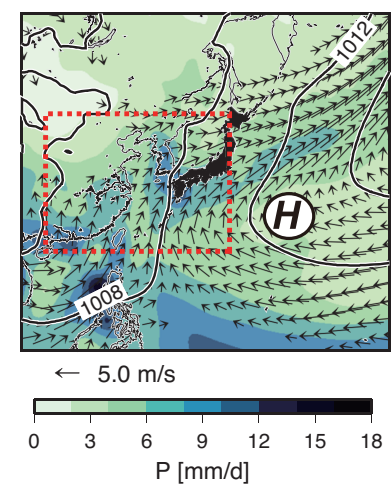

b) DJF

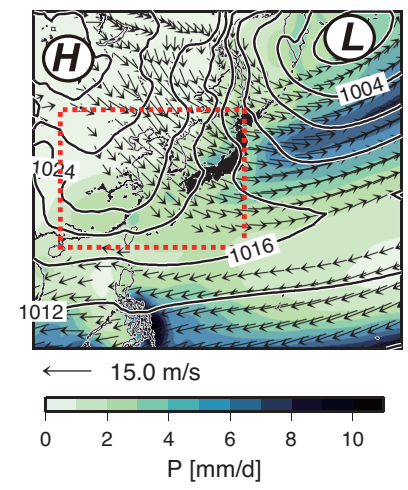

Figure 1. Climatological fields of precipitation (shading), sea level pressure (solid contours, contour interval $4 \mathrm{hPa}$ ) and surface wind (vectors: $\mathrm{m} \mathrm{s}^{-1}$ ) for East Asia during (a) summer (JJA) and (b) winter (DJF). The symbols $\mathrm{H}$ and $\mathrm{L}$ are centers of high and low surface air pressure, respectively. The dotted box represents the East Asian monsoon region defined by Ding and Chan (2005).

and relationship to climate change is of pivotal importance for assessing the impact of future climate change.

Over the past few decades, many studies, using various natural archives such as loess-paleosol (e.g., An et al., 1991; Porter, 2001), lake sediments (e.g., Nakagawa et al., 2006; Yancheva et al., 2007), marine sediments (Kubota et al., 2014), tree ring cellulose (Liu et al., 2004, 2008), and stalagmites (e.g., Wang et al., 2001; Yuan et al., 2004; Hu et al., 2008; Zhang et al., 2008; Cheng et al., 2009), have documented the evolution and variability of the EAM. Among these paleoarchives, stalagmites have been commonly used to reconstruct the EAM because they offer a precise chronology and a high temporal resolution record. Generally, the EAM is divided into a warm and wet summer monsoon (EASM) and a cold and dry winter monsoon (EAWM) (Fig. 1). The stalagmite oxygen isotope records are regarded as a proxy for the amount of the EASM rainfall or the EASM intensity (e.g., Wang et al., 2005; Cai et al., 2010; Liu et al., 2014). The strong EASM periods correspond to a depleted oxygen isotope value in stalagmite, reflecting increased EASM rainfall with relatively lower oxygen isotope values. In the case of the weak EASM periods, decreasing EASM rainfall leads to richer isotopic values in stalagmite. However, these paleomonsoon data are not obtained from the whole EAM region, but are concentrated in China. As shown in Fig. 1, the EAM region receives moisture from both the Pacific Ocean and the South China Sea (SCS) during the summer rainy season. The moisture for summer precipitation over China is transported by southwesterlies from the SCS. Consequently, the oxygen isotope variations in Chinese stalagmites may be influenced to large extent by the variability of southwesterlies from the SCS (Yang et al., 2014). To understand the past EASM variability in the whole region,

the monsoon activity over the Pacific should be considered. Over the Pacific Ocean, the variability of the southerly monsoonal flow is associated with the development of the Bonin High, which is the western part of the North Pacific Subtropical High. Southerly winds along the western edge of the Bonin High transport moisture for precipitation to northeast Asia, including Japan and Korea (Fig. 1). Anomalous intensification/weakening of the Bonin High induces change in precipitation during the summer monsoon (rainy) season in the northeastern countries (Ha and Lee, 2007; Kosaka et al., 2011). Due to the precipitation change in response to monsoon activity, we anticipate that reconstruction of the past monsoon variability in this region from stalagmite or tree ring cellulose, which preserve a record of isotopic variation in precipitation, is possible. However, a major difference of the isotopic composition in between Chinese and Japanese precipitation lies in seasonal contrasts. For example, at the Hulu Cave site in China, $80 \%$ of the precipitation falls during the summer monsoon season (June to September), and the oxygen isotope values in summer precipitation is $10 \%$ lower than those in winter precipitation (Wang et al., 2001). In contrast, in Tokyo, Japan, the oxygen isotopic value in summer rainy season is not lower than that in the dry winter season and the seasonal difference is less than 3\%o (AraguásAraguás et al., 1998). Thus, to reconstruct the past monsoon variability in the northeastern East Asian monsoon countries from stalagmites or tree ring cellulose, we need to clarify the relationship between the isotopic content in precipitation and the monsoon circulation, and to provide a comprehensive physical explanation for how the East Asian Monsoon variability influences the isotopic composition of precipitation.

\subsection{Atmospheric circulation controls on the isotopic composition of mid-latitude precipitation}

Northeast Asia is positioned on the boundary between the area where the seasonal variation in the precipitation isotope ratio is controlled by temperature (high latitude regions) and the area controlled by precipitation amount (lower latitude regions; Bowen, 2008). For mid-latitude regions, the number of studies using event or daily-based isotope data are rapidly increasing in an effort to identify the climate drivers controlling isotopic variability on a seasonal to an annual time scale. For example, in the United States, interevent isotopic variations in response to changes in storm track have been reported (Lawrence et al., 1982; Friedman, 2002; Burnett et al., 2004). Recently, Berkelhammer et al. (2012) showed that changes in vapor sources are manifest in the isotopic composition of precipitation that falls along the western coast of the US. The most isotopically enriched values occur over California when storms supply subtropical marine air with relatively enriched isotopic values from the Pacific. In contrast, storms bringing moisture from the northern Gulf of Alaska are related to the most de- 
pleted events. The same feature has been reported for Irish (Dublin) precipitation in northwestern Europe (Baldini et al., 2010). The results of observation in southern Australia revealed the close relationship of isotopes in precipitation to the prevailing synoptic scale weather pattern (Treble et al., 2005; Barras and Simmonds, 2008, 2009; Crawford et al., 2013). These results demonstrate that isotopic variability in individual local precipitation is closely related to the synoptic scale meteorological conditions. This interpretation is consistent with the results from analyses of controls on interannual variability of isotopes in mid-latitude precipitation using historical monthly-based isotope records archived in the GNIP, coordinated by the International Atomic Energy Agency (IAEA) in cooperation with the World Meteorological Organization (WMO; e.g., IAEA-WMO, 2013). Recent studies showed that inter-annual isotopic variability in European winter precipitation is related to the North Atlantic Oscillation (NAO) index (Baldini et al., 2008; Casado et al., 2013) and hemisphere-wide teleconnections associated with the Arctic Oscillation (AO; Field, 2010). Birks and Edwards (2009) found a strong Pacific-North American (PNA) control on isotopic composition of Canadian winter precipitation. These new findings demonstrate that the variability in the isotopic composition of seasonal precipitation occurs in response to changes in the pattern of meridional atmospheric circulation. Therefore, coupled with the findings from the event-based record of precipitation isotopes, we can say that isotopic variation in mid-latitude precipitation is not directly controlled by temperature and precipitation amounts, but that it mostly depends on meridional atmospheric circulation. The EAM is characterized by the seasonal reversal of the meridional moisture flow, so that the isotopic variation in northeast Asian precipitation would reflect the EAM activity. Proving the last statement in order to provide a seamless explanation of isotopic variability in association with monsoon circulation at multiple temporal scales (inter-annual, seasonal, and event scales) will require clearly showing that changes in short-term isotopic variability affect inter-annual isotopic variations.

\subsection{Outline}

The central purpose of this study is to improve our knowledge of how the EAM variability influences the isotopic composition of northeast Asian precipitation. In this study, using new 1-year long event-based isotope values in precipitation and long-term records of monthly isotopes in precipitation in central Japan, we sought to unveil the mechanism that exerts monsoon circulation controls on isotopic composition in precipitation at multiple time scales from event to interannual scales. A historical 17-year record of oxygen and hydrogen isotopic composition of precipitation at Tokyo station is archived in the GNIP data set. The 17-year-long Tokyo station GNIP record provides enough information for a discussion of the physical structure of the inter-annual isotopic variability in response to changes in monsoon circulation. First, we identified key atmospheric processes controlling the storm-to-storm isotopic variations through an analysis of back trajectories and classification of precipitation systems. Then we applied the identified processes to explain interannual variability and examine how changes in the EAM activity affect the isotopic composition in Japanese precipitation.

\section{Data and methods}

\subsection{Climate summary at observation site}

The isotope observation was conducted at Nagoya $\left(35.15^{\circ} \mathrm{N}\right.$ $136.97^{\circ} \mathrm{E}, 50 \mathrm{~m}$ a.s.l.) located on the Pacific side of central Japan (Fig. 2a). The mean annual rainfall at Nagoya is about $1500 \mathrm{~mm}$, falling almost entirely as rain. The precipitation in summer is much greater than that in winter. GNIP Tokyo station is also located on the Pacific side. The climate in Japan has clear seasonal differences due to the influence of the seasonal reversal of monsoon wind. The summer monsoon season is characterized by two active rainfall periods separated by a break phase (see Ding and Chan, 2005; Ninomiya and Murakami, 1987, for a detailed review). The first rainy period is the northward-migrating rainband known as Baiu in Japan. This Baiu rainband forms on the boundary between the maritime tropical air mass and both continental and maritime polar air masses, and is maintained by moisture supplied by southerly monsoon winds. The Baiu rainband appears in mid-May in the southernmost regions of Japan, and then migrates slowly northward across Japan from early June to mid-July. In mid-July, the Baiu rainband rapidly jumps to northern China and Korea, ending the first rainy period. At the end of August, the Baiu, which had moved northward in early summer, retreats southward to begin the second rainy period that runs from the end of August to early October (called Akisame in Japan). At the Pacific side in central Japan, the second rainy period is not so obvious compared with the first period. In addition to the Baiu and Akisame rainfall, typhoons occasionally bring large amounts of rainfall to Japan in the summer season. The number of typhoons approaching the Japanese archipelago is much higher in boreal and late summer than in the first rainy period.

In winter, the low-level winds reverse primarily from southerlies to northwesterlies (Fig. 1b). The Siberian anticyclone (called the Siberian High) sits over the eastern Siberia with a strong Aleutian low pressure to its east, pushing away the accumulated cold from Siberia with northwesterlies along the eastern frank of the Siberian High (e.g., Chang and Hitchman, 1982). The subsequent cold and dry airflow into the relatively warmer ocean triggers enhanced evaporation and convective activity over the Japan Sea (e.g., Manabe, 1957; Ninomiya, 1968). Therefore, winters are snowy all along the Japan Sea coast. In contrast, the weather is sunny 
a) JJA

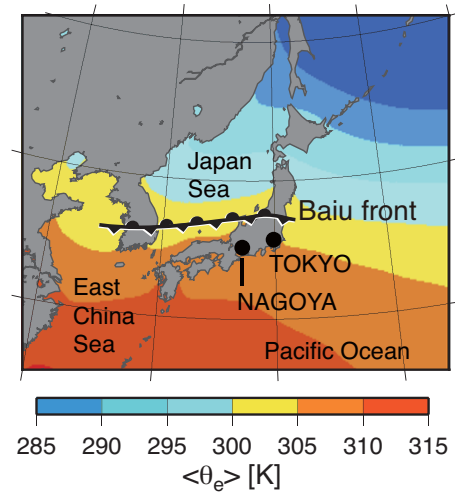

b) DJF

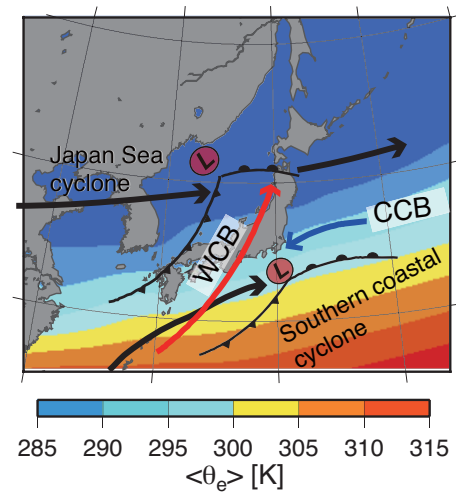

Figure 2. Seasonal mean field of vertically averaged ( $850-925 \mathrm{hPa}$ ) equivalent potential temperatures $\left\langle\theta_{\mathrm{e}}\right\rangle$ (shading over the oceans: K) during (a) summer (JJA) and (b) winter (DJF). The black circle represents the observation site locations (Nagoya and Tokyo). The solid black lines represent typical cyclone tracks (southern coastal cyclone and Japan Sea cyclone) over the Japan archipelago during winter. The red and blue arrows represent the warm conveyor belt (WCB), and the cold conveyor belt (CCB), respectively.

and bright along the Pacific side because most of the snow falls out as the air mass traverses the mountain range that runs centrally along Japan. On the Pacific side, winter precipitation is usually brought by extratropical cyclones advecting off the southern coast of Japan (called southern coastal cyclones) and associated fronts embedded in the cyclone passing through the Japan Sea (called Japan Sea cyclone; Chen et al., 1991; Kusaka and Kitahara, 2009; Adachi and Kimura, 2007; see Fig. 2b).

\subsection{Isotope observation}

A 1-year long event-based precipitation sampling and continuous measurements of water isotopes were conducted at the campus of Nagoya University from June 2013 to June 2014. Throughout this paper, the isotopic concentrations are expressed in $\delta$ notation: $\delta \mathrm{D}$ or $\delta^{18} \mathrm{O}=\left(\frac{R_{\text {sample }}}{R_{\text {V-SMOW }}}-1\right) \times 1000$, where $R$ is the isotopic ratio $\left(\mathrm{HDO} / \mathrm{H}_{2} \mathrm{O}\right.$ or $\mathrm{H}_{2}^{18} \mathrm{O} / \mathrm{H}_{2}^{16} \mathrm{O}$ ). $\mathrm{V}$-SMOW is Vienna Standard Mean Ocean Water.

Precipitation samples were collected in a capped highdensity polyethylene (HDPE) bottle with a plastic funnel when precipitation was not observed in the previous few hours or at 8 a.m. local time (LT) if precipitation had ended at midnight. To prevent post-evaporation from the collected samples, stable isotope analysis was performed as soon as possible after the collection using cavity ring-down spectroscopy isotopic water analysis (model L1102-i; Picarro Inc., Sunnyvale, CA, USA) with a CTC Analytics autosampler (model HTC-PAL; Leap Technologies, Carrboro, NC, USA). Measurement precision was better than $\pm 0.2 \%$ o for $\delta^{18} \mathrm{O}$ and $\pm 2.0 \%$ for $\delta \mathrm{D}$. Analytical uncertainty in d-excess for our measurements was better than $2.6 \%$.

Water vapor isotopic composition was measured using both a WVIA (model DLT-100) manufactured by Los Gatos Research Inc. (LGR Inc., Mountain View, CA, USA) and a conventional cold trap method, which was used in $\mathrm{Ku}$ rita (2013). Outdoor air (15 $\mathrm{m}$ above the ground) was drawn to the WVIA and the cold trap system with a $5 \mathrm{~m}$ length of Teflon tubing via the external pump at a flow rate of $1.5 \mathrm{~L} \mathrm{~min}^{-1}$. As for laser-based measurement, $\delta \mathrm{D}$ and $\delta^{18} \mathrm{O}$ in the ambient air were recorded by the WVIA at $1 \mathrm{~Hz}$. On the other hand, water vapor samples were collected in the trap at $8 \mathrm{a} . \mathrm{m}$. LT every day and were analyzed by the same method as for precipitation samples. Data calibration for laser-based measurement followed the procedure developed by Kurita et al. (2012), without correction for timedependent isotope drift. For $\delta \mathrm{D}$ measurements, the instrumental drift was less than the analytical error related to the cold trap method, although the instrumental drift in $\delta^{18} \mathrm{O}$ values cannot be deemed negligible compared with the results obtained from the cold trap approach. Here, therefore, we focus on $\delta \mathrm{D}$ data. The $\mathrm{H}_{2} \mathrm{O}$ concentration- $\delta \mathrm{D}$ response was evaluated by humidity bias defined as the $\delta \mathrm{D}$ difference of water vapor between WVIA data and cold trap samples at each $\mathrm{H}_{2} \mathrm{O}$ concentration. We calculated a second order polynomial fitting curve using 1-year long humidity bias data, and then applied it for calibrating the $\mathrm{H}_{2} \mathrm{O}$-concentration dependence. To evaluate the validity of WVIA-measured $\delta \mathrm{D}$ values, the corrected WVIA data were compared to the results obtained from the cold trap approach. We calculated the time-averaged WVIA-measured $\delta \mathrm{D}$ values during vapor trapping and then compared them with the cold trap values for the same sampling periods. The day-to-day variation of the $\delta \mathrm{D}$ from cold trap samples matched the WVIA values as expected, although the short-term variation (within a day) could not be resolved by the measurement using the trapping approach. The mean value of the deviations of 298 samples was $0.4 \pm 2.8 \%$. This value is worse than the analytical error associated with the cold trap method $( \pm 2.0 \%)$, but is acceptably smaller than the natural variability. The optimum aver- 
age time of the WVIA was examined using the Allan variance method (Werle et al., 1993) by Sturm and Knohl (2010) who concluded that the highest precision was obtained from a 10 to $15 \mathrm{~min}$ average. We therefore used $10 \mathrm{~min}$-average data for the analysis.

The long-term records of the oxygen isotopic composition of precipitation $\left(\delta^{18} \mathrm{O}\right)$ at the Tokyo station $\left(35.7^{\circ} \mathrm{N}\right.$ $139.8^{\circ} \mathrm{E}, 4$ m a.s.l.) archived in the GNIP database were used to examine the inter-annual seasonal isotopic variation. The data consists of monthly precipitation samples and are available from 1962 to 1979 . The variation in the oxygen isotopic content of precipitation mirrors that of the hydrogen isotopic content.

\subsection{Meteorological data}

Surface meteorological data were obtained from the local meteorological observatory located nearest each isotope monitoring station (Nagoya University and GNIP Tokyo station). Hourly meteorological variables such as barometric pressure, relative humidity, air temperature, wind speed, wind direction, incoming solar radiation, and precipitation amounts are available from the Japan Meteorological Agency (JMA; http://www.data.jma.go.jp/gmd/risk/obsdl). As for large-scale precipitation field data, radar precipitation data calibrated with rain gauge observations (RadarAMeDAS precipitation data) provided by JMA was used in this study. Radar-AMeDAS is 10 min data that entirely covers all the Japanese islands and the adjacent oceans. The horizontal resolution of this data is $5 \mathrm{~km}$. Data is available from 1988. The Japanese 55-year reanalysis project (JRA55) data set (Ebita et al., 2011) were used to examine synoptic scale weather condition. The JRA-55 data are on a horizontal $1.25^{\circ} \times 1.25^{\circ}$ grid with 37 vertical layers from 1000 to $1 \mathrm{hPa}$.

\subsection{Back trajectory analysis}

To estimate cumulative precipitation during the transport along the air mass pathway, backward air mass trajectories were calculated for each precipitation event using the Hybrid Single-Particle Lagrangian Integrated Trajectory (HYSPLIT) Model (Version 4.0) provided by the National Oceanographic and Atmospheric Administration Air Resources Laboratory (NOAA ARL; Draxler and Rolph, 2003). Wind fields were provided by NCEP (National Center for Environmental Prediction). Global data assimilation system (GDAS), which is a $1.0^{\circ} \times 1.0^{\circ}$ horizontal grid, were used as forcing data. Trajectories were calculated from nine different points around the observation site $\left(0.5^{\circ} \times 0.5^{\circ}\right)$ at hourly intervals while rainfall was recorded at the site. Each 30 min position along the $24 \mathrm{~h}$ back trajectories was archived. This $24 \mathrm{~h}$ duration was selected as it is sufficient to record the final transport of air masses from oceanic source regions to the site. The cumulative rainfall $\left(P_{\text {cumul }}\right)$ was calculated as the sum of pre- cipitation along the trajectories before arriving at the site. In order to obtain the time average value during each event, the calculated cumulative precipitation was weighted by the observed hourly precipitation amount at the measurement site:

$P_{\text {cumul }}=\frac{\sum_{t=0}^{m} R_{t}\left(\sum_{i=0}^{n} P_{i} / n\right)}{\sum_{t=0}^{m} R_{t}}$,

where the subscript $m$ indicates total rainfall hours and $n$ represents the number of trajectories at each hour, $P_{i}$ is the cumulative rainfall for each trajectory, and $R_{t}$ is the recorded rainfall amount at the site. In this study, cumulative rainfall corresponds to total precipitation, while air masses travel through the precipitation system that provides rainfall at the observation site. The Japanese precipitation mostly originates from the surrounding oceans (Yoshimura et al., 2004). The spatial distribution of isotopic composition of marine vapor is homogeneous in these areas (Kurita, 2013). Based on these findings, we assume that the isotopic content in source vapor that feeds the precipitation system is less sensitive to the past rainout history over several days. As precipitation intensity exhibits remarkable spatiotemporal variability over a precipitating area, high spatial and temporal resolution precipitation data was used to obtain precise cumulative rainfall. Here, we used 30 min averaged Radar-AMeDAS data, which was re-gridded to a $0.5^{\circ}$ resolution to estimate precipitation amount at each trajectory position.

\subsection{Precipitation classification}

In the EASM season, a quasi-stationary rainband appears at the boundary between warm air and relatively cold air and is characterized by a large gradient of equivalent potential temperature $\theta_{\mathrm{e}}$ (Ninomiya, 1984; see Fig. 2a). At the center of this rainband, $\theta_{\mathrm{e}}$ in the lower atmosphere is around $335 \mathrm{~K}$ and $\theta_{\mathrm{e}}$ gradually decreases (increases) toward the north (south; Tomita et al., 2011; Kanada et al., 2012). In this study, we calculated the vertically averaged (925$850 \mathrm{hPa}$ ) equivalent potential temperature $\left\langle\theta_{\mathrm{e}}\right\rangle$ around the observation site, and then the summer precipitation was divided into warm and cold events depending on the $\left\langle\theta_{\mathrm{e}}\right\rangle$ of the air mass-induced precipitation. The warm rainfall event produced by (sub)tropical maritime air mass was defined as (1) those that $\left\langle\theta_{\mathrm{e}}\right\rangle$ exceed $335 \mathrm{~K}$ around the observation site, or (2) the southerlies from the subtropics regions $\left(\left\langle\theta_{\mathrm{e}}\right\rangle>335 \mathrm{~K}\right)$ that transport moisture to feed rain-bearing systems over the observation site. On the other hand, cold rainfall events were defined as residual cases, or those that did not satisfy both conditions.

In the EAWM season, the precipitation events were classified into three types of cyclonic precipitation and into others (O-type). The surface cyclones were identified using the 6-hourly sea level pressure (SLP) field in the JRA-55 data set, and the cyclonic precipitation events were classified depending on the route for cyclones as follows: Japan Sea cyclone (J-type); southern coastal cyclone (S-type); and inter- 

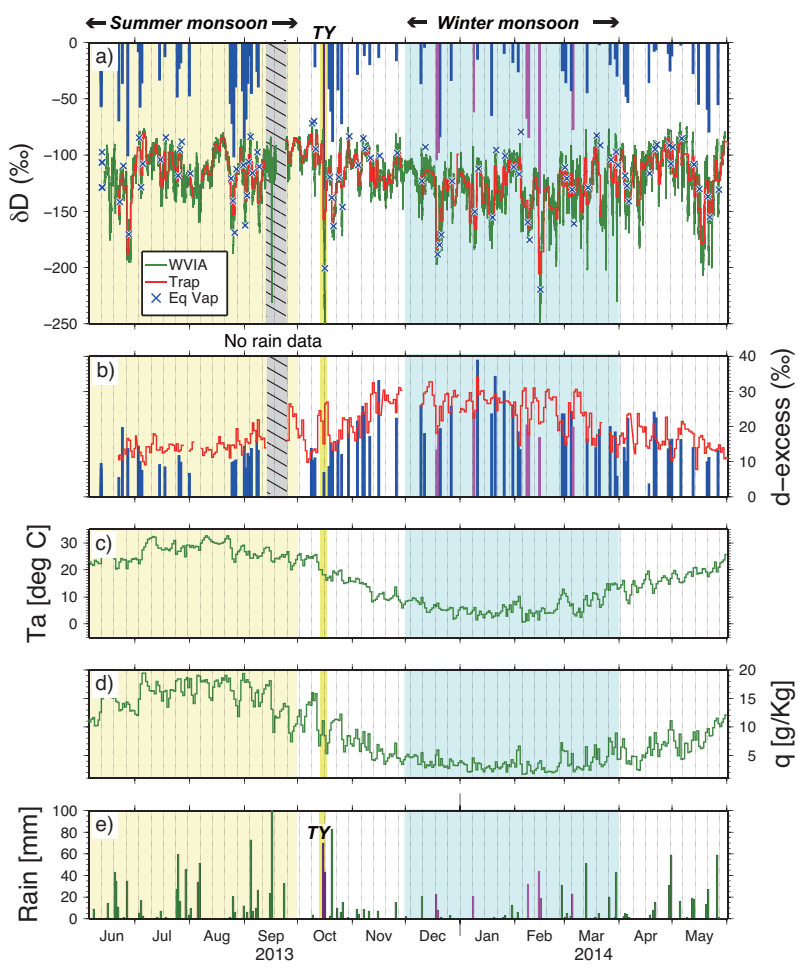

Figure 3. Time series of isotopic values and surface meteorological variables at Nagoya in Japan for the period of June 2013 to June 2014 (summer: shaded in light yellow; winter: shaded in sky blue). (a) $\delta \mathrm{D}$ in precipitation (bar) and surface vapor measured by the laser instrument (green line) and by the conventional cold trap method (red line). The black cross represents the calculated $\delta \mathrm{D}$ of vapor in isotopic equilibrium with precipitation at surface air temperature. The pink-colored bars represent rainfall from Nangan cyclones. (b) The d-excess in precipitation and surface vapor measured by the cold trap method. (c) Air temperature, (d) mixing ratio and (e) precipitation observed at the nearest meteorological station. The "TY" at the top of the figure corresponds to the passage of a typhoon at the observation site.

mediate cyclone type (I-type). The Japan Sea cyclone type corresponds to the rainfall from the frontal system related to the Japan Sea cyclone. The southern coastal cyclone type is a cold rainfall or snowfall event that occurs at the north of the surface warm front moving eastward along the southern coast of Japan. Intermediate type cyclones travel over the main island of Japan, with the center of the cyclones passing near the study site. Although most precipitation events are driven by extratropical cyclone connected with fronts, occasionally small-scale convective clouds traveled from the coast of the Sea of Japan, bringing weak snowfall or rainfall to the site (O-type).

\section{Results}

\subsection{Seasonal cycle}

One-year records of $\delta \mathrm{D}$ in both water vapor and precipitation are shown in Fig. 3, together with temporal variation in meteorological variables. Continuous $\delta \mathrm{D}$ variation in surface vapor shows that the seasonal cycle is weak, and that sub-monthly or intra-seasonal variation is dominant. This contrasts with meteorological variables (surface air tempera- ture, water vapor concentration, and precipitation amounts), which exhibit distinct seasonality with the maximum value in summer and the minimum in winter. Additionally, clear seasonality of the d-excess obtained from cold trap samples, with higher values in winter and lower values in summer, is seen in Fig. 3b. This reflects the change in d-excess over oceanic source regions by the reversal of the monsoon wind direction. In winter, northerly winds push cold and dry continental air over Japan and the adjacent ocean. Evaporation occurs under conditions with a large humidity deficit and a strong temperature contrast between the surface air temperature and the sea surface temperature. As noted previously by numerous studies (e.g., Gat et al., 2003; Uemura et al., 2008), this leads to relatively high d-excess in marine vapor. In contrast, in summer, because evaporation occurs under humid condition, d-excess in a maritime air surrounding Japan is much lower than that in winter (Kurita, 2013). Weak seasonality of $\delta \mathrm{D}$ in surface vapor means that isotopic changes over the oceanic regions have only a minor impact on the $\delta \mathrm{D}$ values in surface vapor. Meanwhile, intraseasonal $\delta \mathrm{D}$ variation is associated with precipitation events. When raindrops fall through the atmosphere, diffusive exchange between raindrops and the surrounding vapor and evaporation of the rain- 

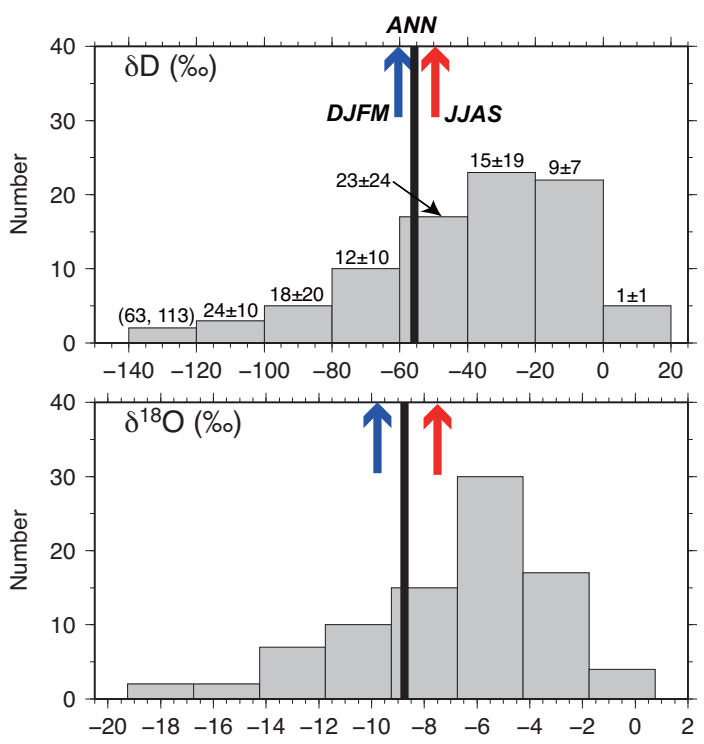

Figure 4. Histograms of (upper panel) $\delta \mathrm{D}$ and (lower panel) $\delta^{18} \mathrm{O}$ values in event-based precipitation. The black line represents the annual mean value weighted by precipitation amount. Blue and red arrows correspond to the winter (DJFM) and summer (JJAS) mean value. The numbers on each bar in the top figure represent average precipitation amount at each bin.

drops takes place, and the $\delta \mathrm{D}$ in vapor tends to be close to the isotopic equilibrium with precipitation (Fig. 3a). The temporal isotopic variability of surface vapor during a year therefore mostly reflects the variation in precipitation. Our time series data highlights the control by short-term isotopic variability on seasonal or more long-term mean isotopic values. This time scale matches well with the synoptic disturbance activity. Hereafter, we focus most of the analysis on stormto-storm isotopic variability in precipitation.

The distribution of $\delta \mathrm{D}$ in individual precipitation events (daily precipitation amount) is shown in Fig. 4a. Interestingly, the precipitation-weighted annual mean $\delta \mathrm{D}$ value $(-56 \%$ ) does not correspond to the dominant bin of $\delta \mathrm{D}$ value, and is significantly lower than the arithmetic mean $(-40 \%$ ). The winter (DJFM) and summer (JJAS) mean values are also lower than the arithmetic mean annual precipitation. The same features can be seen in $\delta^{18} \mathrm{O}$ (Fig. 4b). These findings suggest that the precipitation events with lower $\delta \mathrm{D}$ values make a larger contribution to the seasonal and annual mean values, and the variability of annual or seasonal mean $\delta \mathrm{D}$ value is attributable to the change in relative contribution of storm events. However, for all the precipitation events $(n=78)$, the negative correlation between $\delta \mathrm{D}$ in precipitation and local precipitation amount (the amount effect) is weak $\left(R^{2}=0.167\right)$. The storm-to-storm isotopic variation may be controlled by not only the local rainout, but also by upstream atmospheric conditions such as moisture sources and rainout history during the transport.

\subsection{Summer precipitation}

During the summer rainy season, sub-synoptic scale rain fronts form between a warm air mass from subtropical maritime regions and a cold air mass from both continental and maritime polar regions. In the first rainy season (Baiu), rainfall occurs in association with the north-south displacement of this front. Notably different equivalent potential temperatures $\left(\theta_{\mathrm{e}}\right)$ characterize the cold and warm air masses (Fig. 2a). $\theta_{\mathrm{e}}$ at the observation site varies considerably depending on the north-south displacement of this front. In addition, as shown in Fig. 5, the temporal variation of $\delta \mathrm{D}$ in surface vapor is associated with changes in vertical average of $\theta_{\mathrm{e}}\left(\left\langle\theta_{\mathrm{e}}\right\rangle\right)$. The highest $\delta \mathrm{D}$ peaks correspond to the southerly flows supplying warm maritime air to the site, while abrupt $\delta \mathrm{D}$ decreases appear in association with a southward shift of cold air mass.

Rainfall events during the second rainy season (Akisame) are usually derived from the low-pressure systems connected with fronts. Low-level southerly winds east of the cyclone transport warm air with high $\left\langle\theta_{\mathrm{e}}\right\rangle$, while relatively cold air with low $\left\langle\theta_{\mathrm{e}}\right\rangle$ is supplied by northerly winds. In Fig. 5, the short-term increases and decreases in $\left\langle\theta_{\mathrm{e}}\right\rangle$ correspond to the passage of the frontal systems and troughs, and similar to those occurring during the first rainy season, $\delta \mathrm{D}$ in surface vapor relates well to the $\left\langle\theta_{\mathrm{e}}\right\rangle$ variations. These features are identical with the results obtained from the observation in 2010 (Kurita et al., 2013). In addition, this temporal isotopic variation mirrors that of precipitation. Relatively high $\delta \mathrm{D}$ in precipitation matches the warm rainfall events, and lower $\delta \mathrm{D}$ is observed when cold air inflow occurred. These are classified as cold rainfall events. We conclude from this that the $\delta \mathrm{D}$ difference between warm- and cold-type rainfall reflects changes in air mass sources. On 24 August (labeled 1 in Fig. 5), $\delta \mathrm{D}$ incoming precipitation was relatively low, although $\left\langle\theta_{\mathrm{e}}\right\rangle$ was similar to that in subtropical air $(>335 \mathrm{~K})$. The weather map showed that southerly winds from the subtropics did not arrive at the observation site and the frontal system was displaced to the south of the observation site. The rainfall event therefore corresponds to cold rain and not warm rain.

We investigate the influence of rainout history from the upstream region. The relationship between the $\delta \mathrm{D}$ in individual precipitation events and cumulative rainfall along the trajectories $\left(P_{\text {cumul }}\right)$ over $9 \mathrm{~h}$ is displayed in Fig. 6a. Although $\delta \mathrm{D}$ of warm rainfall events are plotted above those from cold events, the gradual decreasing trend in $\delta \mathrm{D}$ with $P_{\text {cumul }}$ is obvious. The correlation coefficient gradually improves with increasing integration time and then reaches the highest value $\left(R^{2}=0.654\right)$ at $9 \mathrm{~h}$ (see inset in Fig. 6a). The sample labeled "2" in Fig. 6a (same as labeled "2" in Fig. 5) was ignored from the regression analysis because this sample was obtained from the downstream-propagating fully developed convective line, in which the influence of vapor recycling associated with mesoscale convective systems may signifi- 


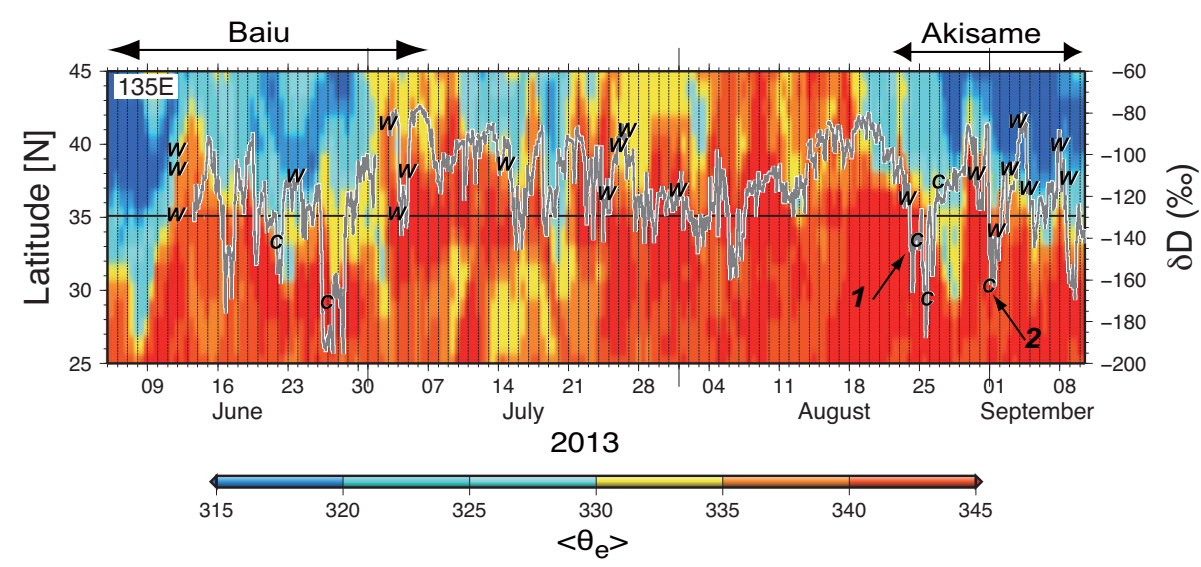

Figure 5. Time series of the value of $\delta \mathrm{D}$ in surface vapor observed at Nagoya University (gray line) and vertically averaged (850-925 hPa) equivalent potential temperatures $\left\langle\theta_{\mathrm{e}}\right\rangle(\mathrm{K})$ between $25^{\circ} \mathrm{N}$ and $45^{\circ} \mathrm{N}$ along $135^{\circ} \mathrm{E}$ during summer (JJAS) in 2013 . The labeled W's (C's) represent the value of $\delta \mathrm{D}$ in surface vapor in equilibrium with warm (cold) type precipitation at the same site.

cantly reduce rainfall $\delta \mathrm{D}$ (Kurita, 2013). The lowest $\delta \mathrm{D}$ was observed with the maximum $P_{\text {cumul }}$ when an intense typhoon passed southeast of the site in the middle of October (labeled TY in Fig. 6a). An intense precipitation area extended from east and north of the center of the typhoon along the cyclonic flow with the site being located in the downstream area of the precipitation (the northwestern side of the typhoon). Also, since northeasterly winds at the northern side of the typhoon transport low $\left\langle\theta_{\mathrm{e}}\right\rangle$ air from the north, the contribution of this air to the typhoon precipitation may act to further decrease $\delta \mathrm{D}$. For summer precipitation, including October, good correlation between $\delta \mathrm{D}$ in precipitation and $P_{\text {cumul }}$ indicates that cumulative precipitation while air mass passed through the rain-bearing systems is a major driver of the storm-to-storm variability in $\delta \mathrm{D}$.

\subsection{Winter precipitation}

In winter, precipitation occurs in association with the passage of eastward-moving extratropical cyclones connected with fronts (see Fig. 2b). We examine the isotopic variability arising from changes in moisture sources. According to the conveyor belt concept (Carlson, 1980), a winter cyclone consists of three major air streams: (a) the warm conveyor belt (WCB); (b) the cold conveyor belt (CCB); and (c) the dry intrusion. The WCB is a stream of relatively warm moist air and originates over the warm waters of Pacific. This air flows northward toward the center of the cyclone and supplies moisture to a warm frontal rainband. The CCB originates to the northeast of the cyclone, and easterly or northeasterly winds north of the cyclone transport this air westward, and feeds a cold frontal rainband. Therefore, the precipitation associated with the cold front mainly originates from the mid- or high-latitude regions.

In the case of the Japan Sea cyclones, the low pressure centers move across the middle of Japan Sea. Figure 7 shows that warm air with high $\left\langle\theta_{\mathrm{e}}\right\rangle$ is injected into the high-latitude region across the observation site when this type of precipitation appeared. The fact that these warm air injections correspond to the highest peaks of $\delta \mathrm{D}$ in surface vapor indicates that the WCB supplies moisture northward with enriched $\delta \mathrm{D}$. Two events of intermediate type (I-type) also show similar features to the Japan Sea type (J-type). This indicates that the WCB reaches near the center of the cyclone. In contrast, the $\delta \mathrm{D}$ depletions occur in association with the passage of the southern coastal cyclones. The major route for the southern coastal cyclone is off the southern coast of Japan from the East China Sea. Unlike the Japan Sea cyclone, a cold rainband fed by the CCB is primarily responsible for precipitation along the Pacific coast of east Japan (Takano, 2002). The CCB transports moisture originating from mid- and highlatitude regions, and as shown by Kurita (2013), the isotopic content of marine surface vapor decreases toward the high latitude regions. Therefore, precipitation in association with the southern coastal cyclone (S-type) is characterized by relatively lower $\delta \mathrm{D}$ values than the others. We further examine the influence of rainout history along the trajectories as an additional source of the $\delta \mathrm{D}$ variability in winter. Excepting Stype events, a robust trend of lower $\delta \mathrm{D}$ with increasing $P_{\text {cumul }}$ is evident in Fig. 6b. However, $\delta \mathrm{D}$ in S-type precipitation are distributed without a clear trend in relation to $P_{\text {cumul }}$ and are plotted below the regression line obtained from both J-type and I-type samples. Two S-type events observed in March (plotted near the regression line) were considered to be I-type rather than S-type because warm air with high $\left\langle\theta_{\mathrm{e}}\right\rangle$ was transported beyond the center of the cyclone and reached near the observation site (Fig. 7). These results indicate that the progressive depletion of $\delta \mathrm{D}$ in vapor-produced rainfall along the pathway from the moisture source region is not a major contributor to large $\delta \mathrm{D}$ depletion in S-type precipitation. Distinctive changes in the isotopic composition of moisture that 

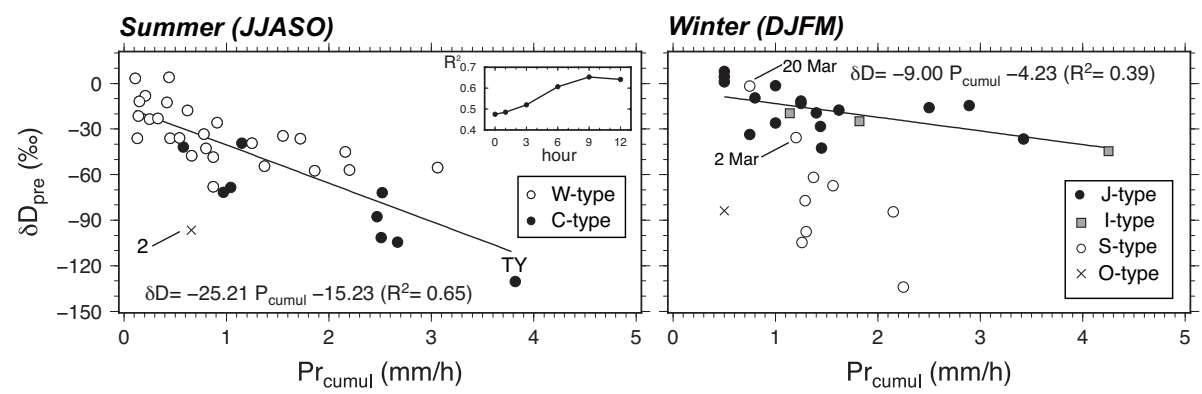

Figure 6. Relationships between $\delta \mathrm{D}$ values in individual precipitation events and cumulative precipitation amount $\left(P_{\text {cumul }}\right)$ over $9 \mathrm{~h}$ back trajectories of the air mass launched from the observation site in (a) summer (from June to October) and (b) winter (December to March). Symbols indicate each different precipitation type (see detail in the text). Inset: variation in the correlation coefficient $\left(R^{2}\right)$ for $\delta \mathrm{D}-P_{\text {cumul }}$ relationship with variation in the period of accumulation. The highest $R^{2}$ values were observed with $9 \mathrm{~h}$ of cumulative precipitation in summer.

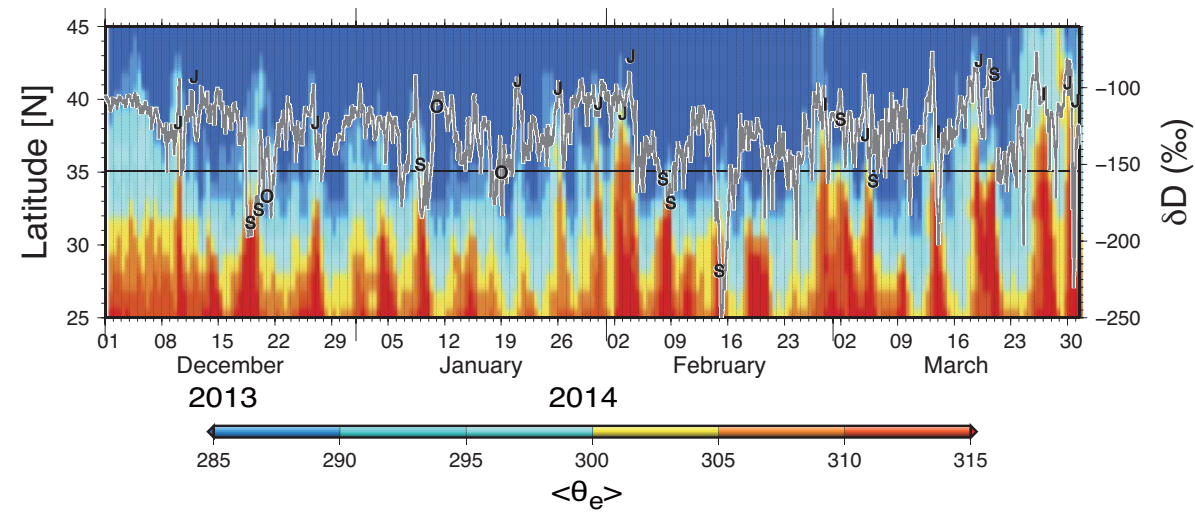

Figure 7. Same as Fig. 5, but represents the time series for the winter (DJFM) season. The labeled characters (J, I, S, O) represent the type of precipitation event as follows: J, Japan Sea-type; I, Intermediate-type; S, southern coastal-type; and O, others-type.

feeds precipitation systems is likely a more important factor influencing the large isotopic variability in winter.

\section{Inter-annual isotopic variation}

Here, using the historical 17-year record of isotopes in precipitation from the GNIP Tokyo station, we examine whether the identified key drivers can account for the inter-annual isotopic variations. In this study we use oxygen isotopes $\delta^{18} \mathrm{O}$ as a substitute for $\delta \mathrm{D}$, because the oxygen isotope record of precipitation in Tokyo has been recorded much longer than for $\delta \mathrm{D}$. The $\delta^{18} \mathrm{O}$ variation of precipitation mirrors that of hydrogen isotopic content.

In summer, $\delta \mathrm{D}\left(\delta^{18} \mathrm{O}\right)$ in individual rainfall events varies widely from event to event, ranging from close to $0 \%$ o $\left(0 \%\right.$ for $\left.\delta^{18} \mathrm{O}\right)$ to less than $-100 \%$ ( $-13 \%$ ), and the wide range of isotopic variability is mainly attributed to the cumulative rainfall along the trajectories (Fig. 6a). To investigate whether this effect is sufficient to explain the interannual isotopic variability, the relationship between isotopic content in precipitation and regional average precipitation amounts is examined. Because the observation period for when monthly precipitation was collected in the GNIP Tokyo station (1962-1979) occurred prior to the availability of the Radar-AMeDAS data, we cannot calculate cumulative rainfall amounts in the same way as mentioned above. The insert in Fig. 6a shows gradual improvement of the correlation coefficient with increasing integration time of $P_{\text {cumul }}$. However $P_{\text {cumul }}$ along the $9 \mathrm{~h}$ trajectories exhibits a good correlation with the values at $0 \mathrm{~h}$ back trajectories $\left(R^{2}=0.653\right.$, $p$ value $<0.01$ ), corresponding to area averaged precipitation $\left(0.5^{\circ} \times 0.5^{\circ}\right)$. This means that we can use area-averaged precipitation amounts as a substitute for cumulative rainfall. The area-averaged rainfall $\left(1.0^{\circ} \times 1.0^{\circ}\right)$ is calculated using Global Precipitation Climatology Center monthly precipitation (GPCC) data set version 6 (Schnider et al., 2011) and then compared with $\delta^{18} \mathrm{O}$ in summer precipitation. The result shows that inter-annual variability in monthly rainfall $\delta^{18} \mathrm{O}$ is completely independent from the precipitation amount. In addition, $\delta^{18} \mathrm{O}$ in the summer-averaged precipitation shows no significant isotopic depletion with precipitation amount $\left(R^{2}=0.076\right)$. Different from the storm-to-storm isotopic variability, rainout history seems not to have a significant influence on the inter-annual variability in the sum- 
mer rainfall $\delta^{18} \mathrm{O}$. Next, we explore the influence of moisture sources on the inter-annual isotopic variation. In summer, southerly flows transport moisture with relatively higher $\delta^{18} \mathrm{O}$, with the warm rainfall type being relatively enriched in heavy isotopes compared with the other rainfall events (Fig. 5). An increase in the contribution of warm rainfall to the total summer precipitation must therefore lead to richer isotopic values in summer average precipitation. Here, we divide daily precipitation into warm and cold events using the $\left\langle\theta_{\mathrm{e}}\right\rangle$ field, and then calculate the cumulative warm rainfall amounts for the summer. To examine how changes in contribution of warm rainfall are manifested in the isotopic values in summer precipitation, we define the warm rain ratio $\left(R_{\mathrm{WR}}\right)$ as the ratio of cumulative warm rainfall to the total summer precipitation. During the period of 1962 to 1979 , the $R_{\mathrm{WR}}$ changes widely year by year, ranging from 0.35 to 0.85 and the inter-annual variation in $\delta^{18} \mathrm{O}$ in summer precipitation matches well with $R_{\mathrm{WR}}$ (Fig. 8a). The correlation between $\delta^{18} \mathrm{O}$ and $R_{\mathrm{WR}}$ for each individual month is as follows: June $\left(R^{2}=0.630\right)$; July $\left(R^{2}=0.719\right)$; August $\left(R^{2}=0.413\right)$; and September $\left(R^{2}=0.719\right)$. This indicates that year-to-year variations in $R_{\mathrm{WR}}$ particularly influence the inter-annual variability in rainfall $\delta^{18} \mathrm{O}$ during the first rainy season (June-July). With more than half of summer precipitation occurring during the first rainy season, a high correlation coefficient $\left(R^{2}=0.627, p\right.$ value $\left.<0.01\right)$ is observed for the precipitation-weighted summer average (Fig. 9a). From this we can conclude that variations in the southerly moisture flux are the primary driver of inter-annual variations in the summer precipitation $\delta^{18} \mathrm{O}$.

Winter precipitation is usually related to extratropical cyclones, and inter-event isotopic variability is linked to their storm tracks. Southerly storms classified as southern coastaltype induce cold precipitation with the most depleted isotope values, as northerly winds bring cold and humid air with lower isotopic values to the observation site. Clearly, the greater the contribution by southern coastal-type precipitation to the total winter precipitation, the more depleted the isotopic content in winter average precipitation will be. Using the SLP field, we identify the date when southern coastal cyclones passed through the site, and then calculate cumulative daily precipitation produced by them during winter season. In this calculation, well-developed cyclones moving off the southern coast of Japan are classified as I-types, because the strengthening southerly flow, corresponding to the WCB, injects warm air further north. As expected, year-to-year variation in the precipitation-weighted $\delta^{18} \mathrm{O}$ in winter precipitation are negatively correlated with the relative contribution of southern coastal-type precipitation to total winter precipitation $\left(R_{\mathrm{S} \text {-type }}\right)$ in Fig. 8d. Here, the winter of 1961 denotes December 1961, January 1962, and February 1962. The positive (negative) peaks of $R_{\mathrm{S} \text {-type }}(1965,1969,1973$ for positive; 1966, 1970, 1976 for negative) match the relatively depleted (enriched) $\delta^{18} \mathrm{O}$ in winter precipitation. Moreover, an abrupt increase of $\delta^{18} \mathrm{O}$ after 1975 occurs concurrently with a clear decreasing trend of $R_{\mathrm{S}-\mathrm{type}}$. Consequently, a statistically robust negative correlation $\left(R^{2}=0.483, p\right.$ value $\left.<0.01\right)$ is observed during the 1962 to 1979 period (Fig. 9b). We can conclude that frequency and intensity of the southern coastal cyclones have a significant impact on both individual precipitation and the winter averaged precipitation $\delta^{18} \mathrm{O}$. Nakamura et al. (2012) have reported that the tracks of southern coastal cyclones varied in association with the meridional shift of the warm ocean current (called Kuroshio) flowing in the south of Japan. The straight path of Kuroshio along the south coast of Japan changed to a meander path state after the year 1975 . The abrupt decrease of $R_{\mathrm{S} \text {-type }}$ after 1975 may be related with this transition of the Kuroshio path.

\section{EAM controls on inter-annual isotopic variability in precipitation}

The historical 17-year record of isotopes in precipitation demonstrates that isotopic variability on an inter-annual time scale is primarily driven by changes in the recurrence of synoptic-scale variations. Here, we examine whether these synoptic-scale changes are forced by the EAM variability. During the summer monsoon season (JJA), a strong or weak EASM year is determined by the activity of the Bonin High (e.g., Ha and Lee, 2007). Anomalous intensification (weakening) of the Bonin High enhances (reduces) the EASM and thus leads to an increase (decrease) in summer precipitation over northeast Asia. Following Ha and Lee (2007), we define the Bonin High index (BHI) by the $500 \mathrm{hPa}$ geopotential height anomaly over the western Pacific area $\left(140-145^{\circ} \mathrm{E}, 25-30^{\circ} \mathrm{N}\right)$. Three strong EASM years (1963, 1969, and 1979) and three weak EASM years (1967, 1972, and 1974) are identified using the BHI time series during 1962 to 1978. Interestingly, these strong and weak EASM years correspond well with the positive and negative $R_{\mathrm{WR}}$ peaks (Fig. 8b). The year-to-year variability of the normalized BHI exhibits a significant negative correlation with $R_{\mathrm{WR}}$ variation from 1962 to $1978(R=-0.66, p$ value $<0.05)$ except for the year of 1966 . The lowest $R_{\mathrm{WR}}$ peak in 1966 was influenced by the passage of an intense typhoon on the southeast side in June. More than $200 \mathrm{~mm}$ of rainfall was induced by the strong northeasterly wind from the northwestern side of the typhoon. A negative BHI- $R_{\mathrm{WR}}$ relationship indicates that the enhanced southerly monsoon flow decreases the relative ratio of precipitation fed by subtropical moisture. To explain this relationship, composite maps of atmospheric circulation and anomalies of the $\left\langle\theta_{\mathrm{e}}\right\rangle$ field for strong and weak monsoon summers are shown in Fig. 10. The strong monsoon summers are characterized by low-level southwesterlies along the northwestern rim of the Bonin High. The enhanced moisture supply to the Baiu rainband in turn augments precipitation around Japan. Anomalous diabatic heating associated with precipitation induces a positive $\left\langle\theta_{\mathrm{e}}\right\rangle$ anomaly along the southern coast of Japan (Fig. 10). This positive anomaly 

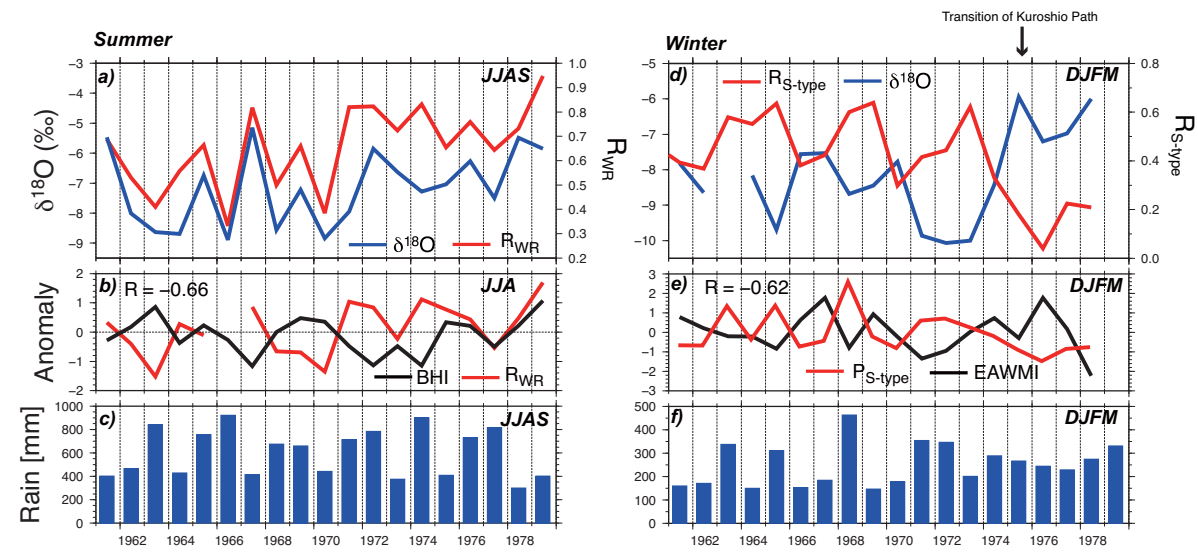

Figure 8. Time series of seasonal average data for the period 1961 to 1979. (a) Precipitation-weighted $\delta^{18} \mathrm{O}$ in summer (June-September) precipitation at Tokyo station and the ratio of the warm rainfall to the total summer precipitation $R_{\mathrm{WR}}$. (b) The $R_{\mathrm{WR}}$ anomaly during boreal summer (June-August) and the Bonin High index (BHI) normalized by standard deviation. (c) The total summer precipitation amount at a meteorological station located near the GNIP Tokyo station. (d) Same as (a), but for winter (December-March) precipitation and for the ratio of the southern coastal cyclone to total winter precipitation $R_{\mathrm{S} \text {-type }}$ (e) Same as (b), but for $R_{\mathrm{S} \text {-type }}$ anomaly during winter and for East Asian Winter Monsoon index (EAWMI). (f) Same as (c), but for winter precipitation.
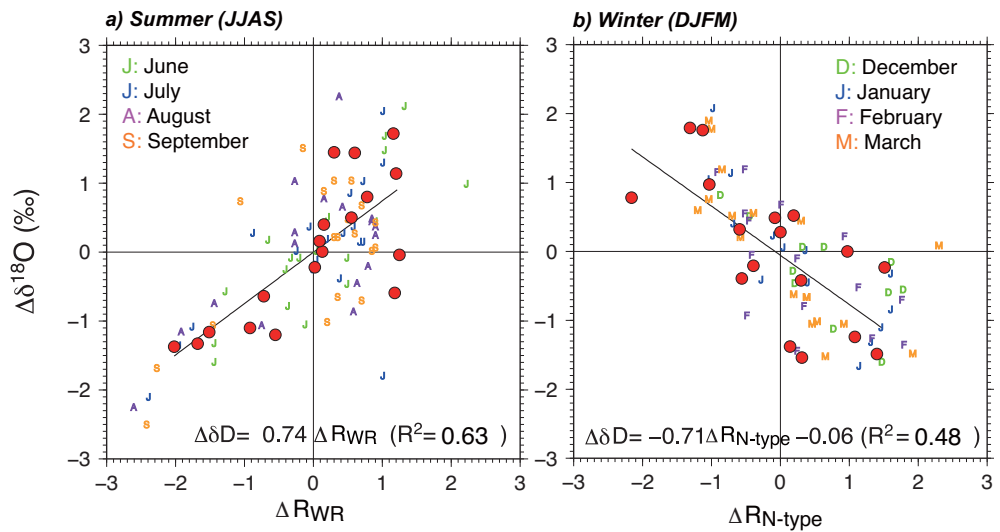

Figure 9. Anomalies of $\delta^{18} \mathrm{O}$ in precipitation at GNIP Tokyo station vs. (a) the ratio of warm rainfall to total summer precipitation ( $R$ WR $)$ and (b) the ratio of the southern coastal precipitation ratio to the total winter precipitation $\left(R_{\mathrm{S} \text {-type }}\right)$. Anomalies for monthly and seasonal averaged values were calculated by subtracting the long-term mean for that month and season and then dividing by the standard deviation. The long-term means were calculated from all available records (1962-1979) at GNIP Tokyo. Red circles represent the precipitation-weighted values in summer (from June to September) and in winter (from December to March).

indicates that the Baiu rainband was frequently located to the south of the observation site, and thus the contribution of the warm-type rainfall would be less than usual. By contrast, the weak EASM years are characterized by southerly winds. Anomalous southerlies over the Pacific may induce large-scale positive $\left\langle\theta_{\mathrm{e}}\right\rangle$ anomaly area over the Pacific and increases the fraction of warm-type rainfall.

In winter, the EAWM intensity is controlled by the pressure gradients between the Aleutian Low and the Siberian High. A steeper pressure gradient results in a more vigorous EAWM over northeast Asia. In this study, the strength of the EAWM is evaluated by the EAWM index (EAWMI), which reflects the $300 \mathrm{hPa}$ meridional wind shear associated with the jet stream (Jhun and Lee, 2004). Figure 8e exhibits the time series of the normalized EAWMI and the S-type precipitation anomalies during the winter monsoon season (DJFM) from 1961 to 1978 . The strong winter monsoon years $(1967,1969,1976)$ and weak winter monsoon years $(1968,1971,1972)$ match the negative and positive anomalies of S-type precipitation. The EAWMI variations are negatively correlated with changes in the S-type precipitation $(R=-0.62, p$ value $<0.05)$. This suggests that the precipitation brought by the southern coastal cyclones is smaller in the strong EAWM years than in the weak EAWM years. The composite maps of $\left\langle\theta_{\mathrm{e}}\right\rangle$ anomalies for strong and weak EAWM shows a clear contrast between the strong and weak monsoon winter years (Fig. 10). In the strong EAWM years, remarkable negative $\left\langle\theta_{\mathrm{e}}\right\rangle$ anomalies caused by cold air out- 


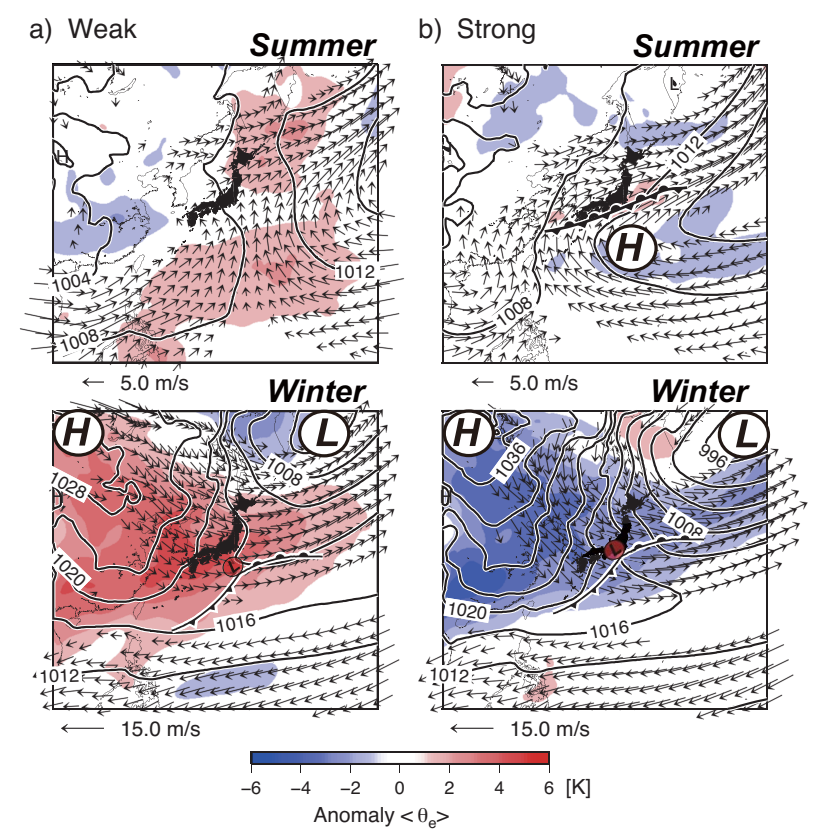

Figure 10. Composite maps of equivalent potential temperatures $\left\langle\theta_{\mathrm{e}}\right\rangle$ anomaly (shading: K) sea level pressure (solid contours, contour interval $4 \mathrm{hPa}$ ) and surface wind (vectors: $\mathrm{ms}^{-1}$ ) for: weak monsoon summers (top left panel); strong monsoon summers (top right panel); weak monsoon winters (bottom left panel); and strong monsoon winters (bottom right panel).

breaks cover the entire northeastern Asia region and the adjacent ocean. The weak EAWM years exhibit exactly opposite behavior. In this region, the heat and moisture flux from the warm ocean is enhanced during the strong EAWM, resulting in favorable conditions for the development of southern coastal cyclones (Yoshiike and Kawamura, 2009). These authors reported that the number of well-developed cyclones is larger in the strong EAWM than in the weak EAWM. As noted in the previous section, the well-developed cyclones are classified as I-types because the strengthening southerly flow transports warm air further north. Therefore, the development of southern coastal cyclones results in decreased Stype precipitation to the site. In addition, it is noteworthy that the storm tracks tend to be concentrated in the vicinity of the south coast of Japan during the strong EAWM years. This indicates that the classification of the extratropical cyclones moving eastward along the Japanese coast tend to be of the I-type. This is consistent with snowfall or cold precipitation events that occur only if the tracks of southern coastal cyclones are distributed away from the south coast of Japan (Nakamura et al., 2012). From these indications, intensified EAWM considerably influences the development and the tracks of the southern coastal cyclones, resulting in decreased S-type precipitation. In contrast, in the weak EAWM years, the distribution of the cyclone tracks away from the southern coast of Japan provides suitable condition for Stype precipitation.
The goal of our study is to unveil the relationship between $\delta^{18} \mathrm{O}$ variability in precipitation and the EAM. We have shown that summer and winter monsoon circulation influence to a large extent the key processes controlling isotopic variability in Japanese precipitation. Therefore, yearto-year variation in the precipitation-weighted $\delta^{18} \mathrm{O}$ in summer precipitation correlates negatively with the BHI between 1962 and $1978(R=-0.47, p$ value $<0.05)$. The winter precipitation $\delta^{18} \mathrm{O}$ is positively correlated with the EAWMI $(R=0.42, p$ value $<0.1)$. These significant correlations are attributed to changes in meridional moisture transport associated with monsoon activity due to the distinctive difference in $\delta^{18} \mathrm{O}$ between low- and high-latitude moisture.

\section{Conclusions}

This study elucidates the mechanism by which the EAM variability influences the isotopic composition of Japanese precipitation. During the summer rainy season, the sub-synoptic scale rainband (Baiu precipitation) forms on the boundary between the warm air mass with relatively enriched isotopic values and the cold air mass with lower isotopic values. The storm-to-storm isotopic variation is linked to a northsouth displacement of this rainband; the higher (lower) isotopic values correspond to the rainband moving north (south) of Japan. On an inter-annual time scale, the Baiu precipitation varies in association with EASM variability. The year-to-year isotopic variability in Japanese precipitation is mostly associated to changes in monsoon circulation. The strong EASM years are characterized by the development of stronger low-level southwesterlies. The enhanced supply of moisture from southwesterlies creates favorable conditions for sustaining the Baiu precipitation along the southern coast of Japan through the rainy season. Consequently, the isotopic composition of summer precipitation is then lower than that of a normal year. The prevailing southwesterly winds in the strong EASM change to southerly winds in the weak EASM. Southerly flows then transport moisture with relatively higher isotopic values from subtropical marine regions, and bring warm precipitation relatively enriched with heavy isotopes compared with the others. As a result, we observe a positive correlation between $\delta^{18} \mathrm{O}$ variability in summer precipitation and the EASM.

In the winter monsoon season, low isotopic values occur when a cold frontal rainband associated with extratropical cyclones (southern coastal cyclones) passes off to the south of the Japan coast. Easterly or northeasterly winds north of the cyclone transport relatively cold air from the mid- or high-latitude regions to the Pacific side of Japan, and feed the cold frontal rainband. Therefore, the precipitation related to the southern coastal cyclone is characterized by relatively lower isotopic values than those from another type of cyclone. It follows that the occurrence of southern coastal cyclones is the most likely contributor to changes in 
the mean isotopic composition of precipitation in the winter. The EAWM variability influences the activity and tracks of the southern coastal cyclones on an inter-annual time scale. The northward shift of the cyclone tracks and stronger development of cyclones during the strong EAWM years are responsible for decreasing the contribution of cold frontal rainfall fed by northerly winds and for increasing isotopic values in winter precipitation. In contrast, in the weak EAWM years, the distribution of cyclone tracks away from the southern coast of Japan provide suitable conditions for cold precipitation, resulting in lower isotopic values in winter precipitation. These results indicate that inter-annual isotopic variability in summer and winter Japanese precipitation is tightly related to the meridional monsoon circulation, which is due to the distinctive difference in isotopic composition between low- and high-latitude moisture. Therefore, the isotopic composition of summer and winter precipitation are significantly correlated with the EASM and EAWM index during the period of 1962 to 1978 . Our data suggest that processes driving the intra-seasonal variability, evidenced thanks to our high resolution event-based sampling, also explain inter-annual variations, in each season. We emphasize however one exception, which is the sharp increase in winter precipitation isotopic composition recorded in 1975. In this case, we attribute this signal to the impact of a transition of the Kuroshio's path.

This improved understanding of processes controlling the isotopic composition of precipitation highlights the importance of large scale drivers. As a result, records of past precipitation isotopic composition that could be obtained from the wealth of natural archives in central Japan (e.g., stalagmites, tree ring cellulose, leaf wax in lake sediments) should have a strong potential to expand the documentation of past changes in summer and winter EAM. Because our study elucidates the climate drivers controlling isotopic variations in summer and winter precipitation, it is important to retrieve a record with seasonal time resolution from paleoarchives.

Acknowledgements. This study has been funded by a grant for environmental research projects from the Sumitomo Foundation (Japan). Most special thanks to our editor, Valérie MassonDelmotte, for her valuable suggestions to improve this manuscript as well as for enthusiastic support throughout the editorial process. We also thank two anonymous reviewers for their constructive comments. The authors gratefully acknowledge the NOAA Air Resources Laboratory (ARL) for the provision of the HYSPLIT transport and dispersion model and the relevant input files for generation of back trajectories. The Radar-AMeDAS data was acquired from the Research Institute for Sustainable Humanosphere (RISH), Kyoto University.

Edited by: V. Masson-Delmotte

\section{References}

Adachi, S. and Kimura, F.: a 36-year climatology of surface cyclogenesis in east Asia using high-resolution reanalysis data, SOLA, 3, 113-116, 2007.

An, Z., Kukla, G., Porter, S., and Xiao, J.: Magnetic susceptibility evidence of monsoon variation on the Loess Plateau of central China during the last 130,000 years, Quaternary Res., 36, 29-36, 1991.

Araguás-Araguás, L., Froehlich, K., and Rozanski, K.: Stable isotope composition of precipitation over southeast Asia, J. Geophys. Res., 103, 28721-28752, doi:10.1029/98JD02582, 1998.

Baldini, L. M., McDermott, F., Foley, A. M., and Baldini, J. U. L.: Spatial variability in the European winter precipitation $\delta^{18} \mathrm{O}$ NAO relationship: Implications for reconstructing NAO-mode climate variability in the Holocene, Geophys. Res. Lett., 35, L04709, doi:10.1029/2007GL032027, 2008.

Baldini, L. M., McDermott, F., Baldini, J. U. L., Fischer, M. J., and Mröllhoff, M.: An investigating of the controls on Irish precipitation $\delta^{18} \mathrm{O}$ values on monthly and event timescales, Clim. Dyn., 35, 977-993, 2010.

Barras, V. and Simmonds, I.: Observation and modeling of stable water isotopes as diagnostics of rainfall dynamics over southeastern Australia, J. Geophys. Res., 114, D23308, doi:10.1029/2009JD012132, 2009.

Barras, V. J. I. and Simmonds, I.: Synoptic controls upon $\delta^{18} \mathrm{O}$ in southern Tasmanian precipitation, Geophys. Res. Lett., 35, L02707, doi:10.1029/2007GL031835, 2008.

Berkelhammer, M., Stott, L., Yoshimura, K., Johnson, K., and Shinha, A.: Synoptic and mesoscale controls on the isotopic composition of precipitation in the western United States, Clim. Dyn., 38, 433-454, 2012.

Birks, S. and Edwards, T.: Atmospheric circulation controls on precipitation isotope-climate relations in western Canada, Tellus, 61B, 566-576, 2009.

Bowen, G.: Spatial analysis of the intra-annual variation of precipitation isotope ratios and its climatological corollaries, J. Geophys. Res., 113, D05113, doi:10.1029/2007JD009295, 2008.

Burnett, A. W., Mullins, H. T., and Patterson, W. P.: Relationship between atmospheric circulation and winter precipitation $\delta^{18} \mathrm{O}$ in central New York State, Geophys. Res. Lett., 31, L22209, doi:10.1029/2004GL021089, 2004.

Cai, Y., Tan, L., Cheng, H., An, Z., Edwards, R., Kelly, M., Kong, $\mathrm{X}$., and Wang, X.: The variation of summer monsoon precipitation in central China since the last deglaciation, Earth Planet. Sci. Lett., 291, 21-31, 2010.

Carlson, T.: Airflow through midlatitude cyclones and the comma cloud pattern, Mon. Wea. Rev., 108, 1498-1509, 1980.

Casado, M., Ortega, P., Masson-Delmotte, V., Risi, C., Swingedouw, D., Daux, V., Genty, D., Maignan, F., Solomina, O., Vinther, B., Viovy, N., and Yiou, P.: Impact of precipitation intermittency on NAO-temperature signals in proxy records, Clim. Past, 9, 871-886, doi:10.5194/cp-9-871-2013, 2013.

Chang, J. H. and Hitchman, M. H.: On the role of successive downstream development in East Asian polar air outbreaks, Mon. Wea Rev., 110, 1224-1237, 1982.

Chen, S.-J., Kuo, Y.-H., Zhang, P.-Z., and Bai, Q.-F.: Synoptic climatology of cyclogenesis over east Asia, 1958-1987, Mon. Wea. Rev., 119, 1407-1418, 1991. 
Cheng, H., Edwards, R., Broecker, W., Denton, G., Kong, X., Wang, Y., Zhang, R., and Wang, X.: Ice Age Terminations, Science, 326, 248-252, 2009.

Crawford, J., Hughes, C. E., and Parkes, S. D.: Is the isotopic composition of event based precipitation driven by moisture source or synoptic scale weather in the Sydney Basin, Australia?, J. Hydrol., 507, 213-226, 2013.

Ding, Y. and Chan, J.: The east Asian summer monsoon: and overview, Meteor. Atmos. Phys., 89, 117-142, 2005.

Draxler, R. and Rolph, G.: Hybrid Singlee-Particle Lagrangian Integrated Trajectory (HYSPLIT), Model released from NOAA ARL READY NOAA Air Resources Laboratory, Silver Spring, MD., http://ready.arl.noaa.gov/HYSPLIT.php (last access: 30 April 2014), 2003.

Ebita, A., Kobayashi, S., Ota, Y., Moriya, M., Kumabe, M. R., Onogi, K., Harada, Y., Yasui, S., Miyaoka, K., Takahashi, K., Kamahori, H., Kobayashi, C., Endo, H., Soma, M., Oikawa, Y., and Ishimizu, T.: The Japanese 55-year Reanalysis JRA-55:An Interim Report, SOLA, 7, 149-152, doi:10.2151/sola.2011-038, 2011.

Field, R. D.: Observed and modeled controls on precipitation $\delta^{18} \mathrm{O}$ over Europe: From local temperature to the Northern Annular Mode, J. Geophys. Res., 115, D12101, doi:10.1029/2009JD013370, 2010.

Friedman, I.: Stable isotpe composition of waters in the Great Basin, United States 1, Air-mass trajectories, J. Geophys. Res., 107, 114, doi:10.1029/2001JD000565, 2002.

Gat, J. R., Klein, B., Kushnir, Y., Roether, W., Wernli, H., Yam, R., and Shemesh, A.: Isotope composition of air moisture over the Mediterranean Sea: and index of the air-sea interaction pattern, Tellus B, 55, 953-965, 2003.

Ha, K.-J. and Lee, S.-S.: On the interannual variability of the Bonin high associated with the east Asian summer monsoon rain, Clim. Dyn., 28, 67-83, 2007.

Hu, C., Henderson, G., Huang, J., Xie, S., Sun, Y., and Johnson, K.: Quantification of Holocene Asian monsoon rainfall from spatially separated cave records, Earth. Planet. Sci. Lett., 266, 221232, 2008

Huang, R., Chen, J., and Huang, G.: Characteristics and variations of the East Asian Monsoon system and its impacts on climate disasters in China, Adv. Atmos. Sci., 24, 993-1023, 2007.

IAEA-WMO: Global Network of Isotopes in Precipitation, The GNIP database, http://www-naweb.iaea.org/napc/ih/IHS resources_gnip.html (last access: 31 March 2013), 2013.

Jhun, J.-G. and Lee, E.-J.: a new east Asian winter monsoon index and associated characteristics of the winter monsoon, J. Clim., 17, 711-726, 2004.

Kanada, S., Nakano, M., and Kato, T.: Projections of future changes in precipitation and the vertical structure of the frontal zone during the Baiu season in the vicinity of Japan using a 5-km-mesh regional climate model, J. Meteor. Soc. Japan, 90A, 65-86, 2012.

Kosaka, Y., Xie, S.-P., and Nakamura, H.: Dynamics of interannual variability in summer precipitation over east Asia, J. Clim., 24, 5435-5453, 2011.

Kubota, Y., Tada, R., and Kimoto, K.: Quantitative reconstruction of East Asian summer monsoon precipitation during the Holocene based on oxygen isotope mass-balance calculation in the East China Sea, Clim. Past Discuss., 10, 1447-1492, doi:10.5194/cpd-10-1447-2014, 2014.
Kurita, N.: Water isotopic variability in response to mesoscale convective system over the tropical ocean, J. Geophys. Res., 118, 10376-10390, doi:10.1002/jgrd.50754, 2013.

Kurita, N., Newman, B. D., Araguas-Araguas, L. J., and Aggarwal, P.: Evaluation of continuous water vapor $\delta \mathrm{D}$ and $\delta^{18} \mathrm{O}$ measurements by off-axis integrated cavity output spectroscopy, Atmos. Meas. Tech., 5, 2069-2080, doi:10.5194/amt-5-2069-2012, 2012.

Kurita, N., Fujiyoshi, Y., Wada, R., Nakayama, T., Matsumi, Y., Hiyama, T., and Muramoto, K.: Isotopic variations associated with north-south displacement of the Baiu Front, SOLA, 9, 187 190, doi:10.2151/sola.2013-042, 2013.

Kusaka, H. and Kitahara, H.: Synoptic-scale climatology of cold frontal precipitation system during the passage over central Japan, SOLA, 5, 61-64, 2009.

Lawrence, J. R., Gedzelman, S. D., White, J. W. C., Smiley, D., and Lazov, P.: Storm trajectories in eastern US D/H isotopic composition of precipitation, Nature, 296, 638-640, 1982.

Liu, W., Feng, X., Liu, Y., Zhang, Q., and An, Z.: $\delta^{18} \mathrm{O}$ values of tree rings as a proxy of monsoon precipitation in arid northwest China, Chem. Geol., 206, 73-80, 2004.

Liu, Y., Cai, Q., Liu, W., Yang, Y., Sun, J., and Song, H.: Monsoon precipitation variation recorded by tree-ring $\delta^{18} \mathrm{O}$ in arid northwest China since AD 1878, Chem. Geol., 252, 56-61, 2008.

Liu, Z., Wen, X., Brady, E., Otto-Bliesner, B., Yu, G., Lu, H., Cheng, H., Wang, Y., Zheng, W., Ding, Y., Edwards, R., Cheng, J., Liu, W., and Yang, H.: Chinese cave records and the east Asia summer monsoon, Quat. Sci. Rev., 83, 115-128, 2014.

Manabe, S.: On the modification of airmass over the Japan Sea when the outburst of cold air predominates, J. Meteor. Soc. Japan, 35, 311-326, 1957.

Nakagawa, T., Tarasov, P., Kitagawa, H., Yasuda, Y., and Gotanda, K.: Seasonal specific responses of the east Asian monsoon to deglacial climate changes, Geology, 34, 521-524, 2006.

Nakamura, H., Nishina, A., and Minobe, S.: Response of storm track to bimodal Kuroshio path states south of Japan, J. Clim., 25, 7772-7779, 2012.

Ninomiya, K.: Heat and water budget over the Japan Sea and the Japan island in winter season, J. Meteor. Soc. Japan, 46, 343372, 1968.

Ninomiya, K.: Characteristics of Baiu front as a predominant subtropical front in the summer northen hemisphere, J. Meteor. Soc. Japan, 62, 880-894, 1984.

Ninomiya, K. and Murakami, T.: The early summer rainy season (Baiu) over Japan, Oxford University Press, 1987.

Porter, S.: Chinese loess record of monsoon climate during the last glacial-interglacial cycle, Earth Sci. Rev., 54, 115-128, 2001.

Schnider, U., Becker, A., Finger, P., Meyer-Christoffer, A., Rudolf, B., and Ziese, M.: GPCC Full Data Reanalysis Version 6.0 at $0.5^{\circ}$ : Monthly Land-Surface Precipitation from Rain-Gauges built on GTS-based and Historic Data, doi:10.5676/DWD_GPCC/FD_M_V6_050, 2011.

Sturm, P. and Knohl, A.: Water vapor $\delta \mathrm{D}$ and $\delta^{18} \mathrm{O}$ measurements using off-axis integrated cavity output spectroscopy, Atmos. Meas. Tech., 3, 67-77, doi:10.5194/amt-3-67-2010, 2010.

Takano, I.: Analysis of an intense winter extratropical cyclone that advanced along the south coast of Japan, J. Meteor. Soc. Japan., $80,669-695,2002$. 
Tao, F., M. Yokozawa, J. L., and Zhang, Z.: Chimate-crop yield relationships at provincial scales in China and the impacts of recent climate trends, Clim. Res., 38, 83-94, 2008.

Tomita, T., Yamaura, T., and Hashimoto, T.: Interannual variability of the Baiu season near Japan evaluated from the equivalent potential temperature, J. Meteor. Soc. Japan, 89, 517-537, 2011.

Treble, P. C., Budd, W. F., Hope, P. K., and Rustomji, P. K.: Synoptic-scale climate patterns associated with rainfall $\delta^{18} \mathrm{O}$ in southern Australia, J. Hydrol., 302, 270-282, 2005.

Trenberth, K., Hurrell, J., and Stepaniak, D.: The Asian monsoon: Global perspectives, in: The Asian Monsoon, edited by Wang, B., chap. 2, 67-87, Springer, 2006.

Uemura, R., Matsui, Y., Yoshimura, K., Motoyama, H., and Yoshida, N.: Evidence of deuterium excess om water vapor as a indicator of ocean surface condition, J. Geophys. Res., 113, D19114, doi:10.1029/2008JD010209, 2008.

Wang, Y., Cheng, H., Edwards, R., He, Y., Kong, X., An, Z., Wu, J., Kelly, M. J., Dykoski, C., and Li, X.: The Holocene Asian monsoon:Links to solar changes and north Atlantic climate, Science, 308, 854-857, 2005.

Wang, Y. J., Cheng, H., Edwards, R. L., An, Z. S., Wu, J. Y., Shen, C.-C., and Dorale, J. A.: a high resolution absolute-dated late Pleistocene monsoon record from Hulu cave, China, Science, 294, 2346-2348, 2001.

Webster, P., Magaña, V., Palmer, T., Shukla, J., Tomas, R., Yanai, M., and Yasunari, T.: Monsoons:Processes, predictability, and the prospects for prediction, J. Geophys. Res., 103, 14451-14510, 1998.
Werle, P., Mücke, R., and Slemr, F.: The limits of signal averaging in atmospheric trace-gas monitoring by tunale diode-laser absorption spectroscopy (TDLAS), Appl. Phys. B, 57, 131-139, 1993.

Yancheva, G., Nowaczyk, N., Mingram, J., Dulski, P., Negendank, J., Liu, J., abd L.C. Peterson, D. S., and Haug, G.: Influence of the intertropical convergence zone on the east Asian monsoon, Nature, 445, 74-77, 2007.

Yang, X., Liu, J., Liang, F., Yuan, D., Yang, Y., Lu, Y., and Chen, F.: Holocene stalagmite $\delta^{18} \mathrm{O}$ records in the East Asian monsoon region and their correlation with those in the Indian monsoon region, The Holocene, 24, 1657-1664, 2014.

Yoshiike, S. and Kawamura, R.: Influence of wintertime large-scale circulation on the explosively developing cyclones over the western North Pacific and their downstream effects, J. Geophys. Res., 114, D13110, doi:10.1029/2009JD011820, 2009.

Yoshimura, K., Oki, T., Ohte, N., and Kanae, S.: Colored moisture analysis estimates of variations in 1998 Asian monsoon water sources, J. Meteorol. Soc. Japan, 82, 1315-1329, 2004.

Yuan, D., Cheng, H., Edwards, R., Dykoski, C. A., Kelly, M., Zhang, M., Qing, J., Lin, Y., Wang, Y., Wu, J., Dorale, J., An, Z., and Cai, Y.: Timing, Duration, and Transitions of the Last Interglacial Asian Monsoon, Science, 304, 575-578, 2004.

Zhang, P., Cheng, H., Edwards, R., Chen, F., Wang, Y., Yang, X., Liu, J., Tan, M., Wang, X., Liu, J., An, C., Dai, Z., Zhou, J., Zhang, D., Jia, J., Jin, K., and Johnson, K.: a Test of Climate, Sun, and Culture Relationships from an 1810-Year Chinese Cave Record, Science, 322, 940-942, 2008. 